\title{
Neurogenic hypertension: introduction to the series
}

\author{
Jose-Alberto Palma ${ }^{1}$ \\ Received: 9 July 2018 / Accepted: 10 July 2018 / Published online: 17 July 2018 \\ c) Springer-Verlag GmbH Germany, part of Springer Nature 2018
}

Keywords Neurogenic hypertension - Supine hypertension · Paroxysmal hypertension · Ambulatory blood pressure monitor $\cdot$ Blood pressure

Neurogenic orthostatic hypotension has been long recognized as one of the landmarks of autonomic dysfunction for decades. That abnormal autonomic function, particularly sympathetic hyperactivity, has a role in the origin, progression and outcome of human hypertension has been also known for long, with renewed interest on this topic in recent years [4, 7], along with further description of relevant systems, such as the endocannabinoid [10]. Echoing this increasing interest, in this issue of Clinical Autonomic Research, expert authors review the diagnosis, pathophysiology, and management of hypertension in the setting of autonomic dysfunction.

The first article of the mini-series is a seminal and highly anticipated expert consensus definition of neurogenic supine hypertension [3]. Neurogenic supine hypertension is an increasingly recognized characteristic of patients with autonomic failure, accompanying neurogenic orthostatic hypotension. Until now, the definition of neurogenic supine hypertension was not defined, resulting in heterogeneous criteria, which hampered replication of study results. The new definition of neurogenic supine hypertension (a systolic blood pressure of at least $140 \mathrm{mmHg}$ and/or a diastolic of at least $90 \mathrm{mmHg}$ measured after, at least, $5 \mathrm{~min}$ in the supine resting position) is simple and straightforward enough to be used and implemented rapidly in the research and clinical settings. Now that there is a definition, standardization of research studies on this topic should be able to bring more light to the issue, and allow future adjustments. Importantly, this definition should contribute to the design and conduct of controlled clinical trials for neurogenic supine hypertension, given that, so far, the treatment options for these patients are

Jose-Alberto Palma

JoseAlberto.PalmaCarazo@nyumc.org

1 Department of Neurology, Dysautonomia Center, New York University School of Medicine, New York, NY 10016, USA merely empirical [2]. Of note, the consensus also highlights the importance of using ambulatory 24-h blood pressure monitoring for improved diagnosis and characterization of neurogenic supine hypertension, as office readings might not be sensitive or accurate enough [9].

Dr. Mann reviews the epidemiology, pathophysiology and management of neurogenic hypertension [8]. He discusses the many subtypes of neurogenic hypertension, including paroxysmal, labile, and acute hypertension, and how the differential diagnosis must include not only afferent baroreflex failure, a diagnosis well known in the autonomic community, but also emotional/psychological factors. Management includes centrally and peripherally acting pharmacological agents, along with non-pharmacological therapy.

In their state-of-the-art review, Linz and colleagues discuss the relevance of renal afferent and efferent sympathetic nerves in blood regulation and hypertension, with focus on the potential of and lessons learned from renal denervation [6]. They further analyze the comorbidities of hypertension that also share sympathetic hyperactivity, such as heart failure, sleep apnea, and atrial fibrillation, and how renal modulation can not only be beneficial for the treatment of hypertension, but also for the management of life-threatening arrhythmias.

Finally, Goldberg and colleagues report their experience with ambulatory 24-h monitoring in patients with familial dysautonomia, a rare genetic disease characterized by inherited afferent baroreflex failure [5]. Not surprisingly, the pattern of patients with familial dysautonomia is consistent with those of patients with acquired baroreflex failure, including very labile blood pressure and abnormal circadian blood pressure rhythm [1]. This adds to the importance of using ambulatory 24-h blood pressure monitoring in patients with suspected neurogenic hypertension.

The editors of Clinical Autonomic Research hope this mini-series is helpful to readers to increase awareness, 
accelerate diagnosis, and improve management of patients with neurogenic hypertension.

Jose-Alberto Palma MD PhD
Managing Editor
Clinical Autonomic Research

Funding source None.

\section{Compliance with ethical standards}

Conflict of interest The authors declare that they have no competing interests.

\section{References}

1. Abuzinadah AR, Sinn DI, Freeman R, Gibbons CH (2016) Blood pressure oscillations in baroreflex failure. Clin Auton Res Off J Clin Auton Res Soc 26:465-466

2. Di Stefano C, Maule S (2018) Treatment of supine hypertension in autonomic failure: a case series. Clin Auton Res Off J Clin Auton Res Soc 28:245-246

3. Fanciulli A, Jordan J, Biaggioni I, Calandra-Buonaura G, Cheshire WP, Cortelli P, Eschlboeck S, Grassi G, Hilz MJ, Kaufmann H, Lahrmann H, Mancia G, Mayer G, Norcliffe-Kaufmann L,
Pavy-Le Traon A, Raj SR, Robertson D, Rocha I, Struhal W, Thijs R, Tsioufis KP, van Dijk JG, Wenning GK (2018) Consensus statement on the definition of neurogenic supine hypertension in cardiovascular autonomic failure by the American Autonomic Society (AAS) and the European Federation of Autonomic Societies (EFAS): endorsed by the European Academy of Neurology (EAN) and the European Society of Hypertension (ESH). Clin Auton Res. https://doi.org/10.1007/s10286-018-0529-8

4. Freitas IMG, de Almeida LB, Pereira NP, Mira PAC, de Paula RB, Martinez DG, Toschi-Dias E, Laterza MC (2017) Baroreflex gain and vasomotor sympathetic modulation in resistant hypertension. Clin Auton Res Off J Clin Auton Res Soc 27:175-184

5. Goldberg L, Bar-Aluma BE, Krauthammer A, Efrati O, Sharabi Y (2018) Ambulatory blood pressure profiles in familial dysautonomia. Clin Auton Res. https://doi.org/10.1007/s10286-018-0507-1

6. Linz D, Hohl M, Elliott AD, Lau DH, Mahfoud F, Esler MD, Sanders P, Bohm M (2018) Modulation of renal sympathetic innervation: recent insights beyond blood pressure control. Clin Auton Res. https://doi.org/10.1007/s10286-018-0508-0

7. Mancia G, Grassi G (2014) The autonomic nervous system and hypertension. Circ Res 114:1804-1814

8. Mann SJ (2018) Neurogenic hypertension: pathophysiology, diagnosis and management. Clin Auton Res. https://doi.org/10.1007/ s10286-018-0541-z

9. Norcliffe-Kaufmann L, Kaufmann H (2014) Is ambulatory blood pressure monitoring useful in patients with chronic autonomic failure? Clin Auton Res Off J Clin Auton Res Soc 24:189-192

10. Sierra S, Luquin N, Navarro-Otano J (2018) The endocannabinoid system in cardiovascular function: novel insights and clinical implications. Clin Auton Res Off J Clin Auton Res Soc 28:35-52 